\title{
Evaluation of the Effective Mechanical Properties of Concrete Composites Using Industrial Waste Carpet Fiber
}

\author{
Hossein Mohammadhosseini ${ }^{1}\left[\right.$ ] Jamaludin Mohamad Yatim ${ }^{1}$
}

Received: 23 September 2016/Accepted: 12 January 2017/Published online: 24 January 2017

(C) Indian National Academy of Engineering 2017

\begin{abstract}
Synthetic waste fibers are cheap and popular materials used in the concrete, and they may positively affect the properties of cementitious composites because of their superior properties. This research proposes the utilization of waste carpet fiber and palm oil fuel ash (POFA) to develop the physical, mechanical and microstructural properties of concrete. Carpet fiber of $20 \mathrm{~mm}$ length and six volume fractions of $0,0.25,0.5,0.75,1.0$ and $1.25 \%$ were used with ordinary Portland cement (OPC). Another six mixes were made that replaced OPC with $20 \%$ POFA. The combination of carpet fiber and POFA decreased the slump values and increased the VeBe time of fresh concrete. Likewise, the addition of carpet fiber, either into OPC or POFA concrete, did not improve the compressive strength. However, the positive interaction between the carpet fiber and POFA lead to higher tensile and flexural strengths. Despite lower strength development, an increment in the post-failure compressive strength of concrete composite was observed in all mixes. A significant enhancement was also observed in impact resistance of the concrete composite containing carpet fiber, as compared to that of plain concrete. Microstructure of concrete was examined by using scanning electron microscope. It is revealed that carpet fibers act as bridges across the cracks, which improve the load-transfer capacity of the matrix. The study showed that the utilization of waste carpet fiber and POFA in the production of concrete is feasible from both technical and environmental points of view.
\end{abstract}

Hossein Mohammadhosseini

hofa2018@yahoo.com

1 Department of Structure and Materials, Faculty of Civil Engineering, Universiti Teknologi Malaysia, UTM, 81310 Skudai, Johor, Malaysia
Keywords Concrete composite - Waste carpet fiber · Palm oil fuel ash . Physical and mechanical properties

\section{Introduction}

Concrete is the most important construction material and its consumption is increasing all around the world. The low tensile strength and the high rigidity of concrete, include it as a brittle material. In addition to the common uses, higher ductility and energy absorption capacity are often essential in different applications such as industrial floors, highway paving and bridge decks (Brandt 2008). In these situations fiber reinforced concrete has been revealed to achieve its functions satisfactorily (Hsie et al. 2008; Zhang et al. 2011). Fiber reinforced concrete (FRC) is a composite material made of ordinary Portland cements (OPC), coarse and fine aggregates, and a dispersion of discontinuous short fibers. Fibers in general and polypropylene fibers, in particular, have increased popularity in the last decades for use in concrete, mostly to improve the shrinkage and cracking resistance of plain concrete (Yap et al. 2013; Mohamadi et al. 2013). Polypropylene fibers are not expected to increase the compressive strength of concrete, but to enhance the ductility, toughness and impact resistance (Karahan and Atis 2011).

Fiber reinforced concrete containing pozzolanic materials has also been made and studied with conventional concrete (Sisomphon and Franke 2007; Lim et al. 2015). There is no doubt that there has been a recent growth of new supplementary cementitious materials (SCM) that afford excellent physical, mechanical and durability properties (Papadakis 2000; Aldahdooh et al. 2014; Mohammadhosseini et al. 2016). These pozzolanic materials are used all over the world for their technical, economic and 
ecological benefits. On the list of recent additions to the ash family is the palm oil fuel ash (POFA), a waste material obtained on burning palm oil husk and palm kernel shell as fuel in palm oil mills. The ash, which is disposed of without any commercial return is now considered a valuable material with a good performance in improving the strength and durability aspects of concrete (Tay and Show 1995; Mohammadhosseini et al. 2015; Khankhaje et al. 2016).

Synthetic fibers are developed mostly to supply the high demand for carpet and textile products. Nylon and polypropylene are the most synthetic fibers used in these industries. The large amount of carpet waste is generated and main part is in the fibrous form. In the USA alone, about 11.9 million tons of textile waste were generated, accounting for $4.7 \%$ of the total municipal solid waste, and $15.9 \%$ of textile waste was recovered in 2007 (Wang 2010; Mohammadhosseini and Awal 2013). Generally, industrial carpet wastes are from face and back yarns. The face yarn is usually polypropylene or nylon fibers and the back yarn is mainly in the form of woven sheets (Fig. 1). These fibers are mainly 50-70\% nylon and $15-25 \%$ polypropylene (Awal and Mohammadhosseini 2016). The advantages of using such recycled fibers include generally lower cost to process than virgin fibers, light in weight, good acid and alkali resistance and non-absorbent of water (Awal et al. 2015; Sotayo et al. 2015).

Research works in the past have demonstrated that the addition of carpet fibers is potential to enhance the properties of concrete (Wang et al. 2000; Schmidt and Cieslak 2008). The combined effect of waste polypropylene carpet fibers and ash as pozzolanic material on the properties of concrete is relatively a new research that needs significant consideration. It is necessary to conduct in-depth study on the performance of concrete with the wide range of mix proportions. Since a low volume fraction of short fibers has been recommended for the development of the strength properties of concrete, it paves the way to use waste carpet
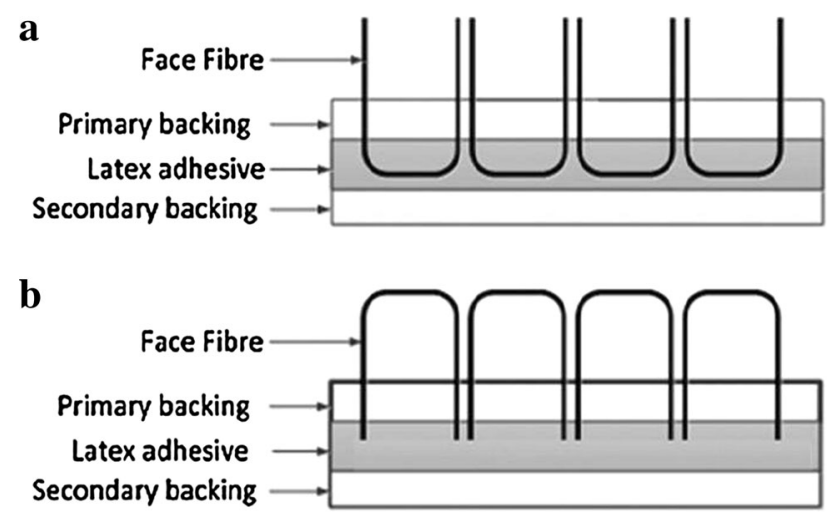

Fig. 1 Typical structure of industrial carpet: a cut-pile b level-loop fibers to get more detail on physical and mechanical properties of concrete containing waste carpet fibers.

The influence of carpet fiber and POFA on the physical and mechanical properties of concrete is not common in the existing literature. Taking into account the availability and the fibrous nature of waste polypropylene carpet fiber, and pozzolanic behavior of POFA, research work on the utilization of the materials have been initiated in the Department of Structure and Materials, Faculty of Civil Engineering of the Universiti of Teknologi Malaysia. The purpose of this study was to investigate the combined effect of palm oil fuel ash and carpet fiber in the development of physical, mechanical and microstructure properties of concrete composites. Properties of concrete such as workability, compressive strength, tensile and flexural strengths, post-failure compressive strength, impact resistance, and ultrasonic pulse velocity tests were examined, and results compared to that of concrete with OPC alone without any fiber.

\section{Materials and Test Methods}

\section{Materials}

In this study ordinary Portland cement (ASTM Type I) was used. Raw POFA was collected from a palm oil mill located in Johor, Malaysia. Initially, POFA was dried and sieved in order to eliminate larger particles and also to reduce the carbon content. Later, particles smaller than $150 \mu \mathrm{m}$ were ground with Los Angeles milling device containing 10 steel bars of $800 \mathrm{~mm}$ length and $12 \mathrm{~mm}$ diameter for a period of 2 hours for each four $\mathrm{kg}$ of POFA. The chemical composition and physical properties of POFA and OPC are given in Table 1 and the scanning electron micrograph (SEM) of POFA is shown in Fig. 2.

Mining sand at the saturated surface dry condition passing through a $4.75 \mathrm{~mm}$ sieve, with fineness modulus and specific gravity of 2.3 and 2.6 respectively, and having a water absorption of $0.70 \%$ was used as fine aggregate. While a crushed granite of $10 \mathrm{~mm}$ maximum size having a specific gravity of 2.7 and $0.5 \%$ water absorption capacity was used as coarse aggregate.

Throughout the study supplied tap water was used for both mixing and curing purposes. A polymer based superplasticizer of RHEOBUILD 1100 (HG), was also used in order to increase the workability of concrete at $1.0 \%$ by weight of cementing materials. A water/binder (w/ b) ratio of 0.47 was kept constant in all batches. In this study, the waste carpet fibers were obtained from ENTEX Carpet Industries Selangor, Malaysia. The waste carpet fibers introduced in the form of the skein of string at different sizes were cut to desired length. The multi-filament 
Table 1 Physical properties and chemical composition of OPC and POFA

\begin{tabular}{llllrr}
\hline Physical properties & OPC & POFA & Chemical composition $(\%)$ & OPC & POFA \\
\hline Specific gravity & 3.15 & 2.42 & $\mathrm{SiO}_{2}$ & 20.4 & 62.60 \\
Blaine fineness $\left(\mathrm{cm}^{2} / \mathrm{g}\right)$ & 3990 & 4930 & $\mathrm{Al}_{2} \mathrm{O}_{3}$ & 5.20 & 4.65 \\
Passing sieve $10 \mu \mathrm{m}(\%)$ & 19 & 33 & $\mathrm{Fe}_{2} \mathrm{O}_{3}$ & 4.19 & 8.12 \\
Soundness $(\mathrm{mm})$ & 1.0 & 2.0 & $\mathrm{CaO}$ & 62.39 & 5.70 \\
& & & $\mathrm{MgO}$ & 1.55 & 3.52 \\
& & & $\mathrm{~K}_{2} \mathrm{O}$ & 0.005 & 9.05 \\
& & & $\mathrm{SO}_{3}$ & 2.11 & 1.16 \\
& & & $\mathrm{LOI}$ & 2.36 & 6.25 \\
\hline
\end{tabular}

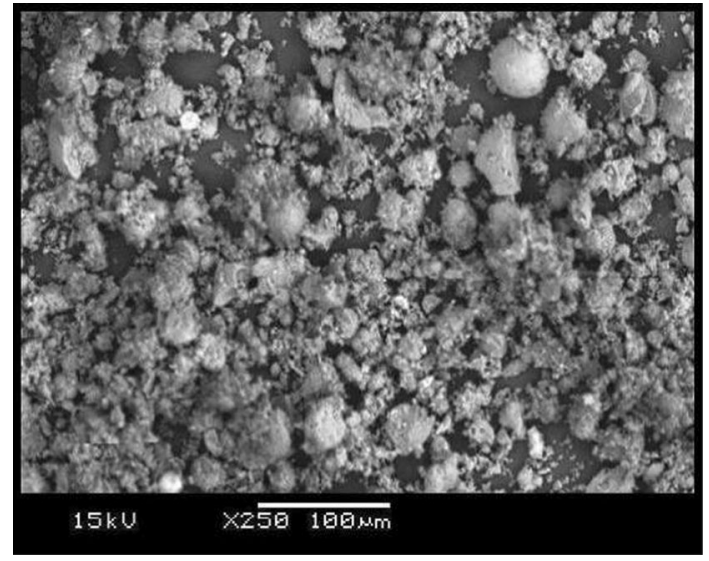

Fig. 2 Scanning electron micrograph of POFA

polypropylene carpet fibers of $20 \mathrm{~mm}$ in length and $0.45 \mathrm{~mm}$ diameter with aspect ratio $(1 / \mathrm{d})$ of 44 were used (Fig. 3), the general properties of carpet fiber being presented in Table 2 and the SEM of waste carpet fiber is revealed in Fig. 4.

\section{Mix Proportioning}

The process of mixing was started with the dry mixing of the fine and coarse aggregates. Cement and POFA were added; the mixing process was continued for about $2 \mathrm{~min}$. Water and superplasticizer were added and mixed for 2 more minutes. After the wet mixing process, the required volume of carpet fibers was added to the mixture while mixing process was going on. The mixing process was continued for about 2 min to ensure that the carpet fibers were consistently dispersed throughout the mix. The mix proportions of fiber reinforced concrete are presented in Table 3. In all, twelve mixture proportions were made where the first one (B1) was considered as control mix without any POFA and fiber. Out of twelve, the first six batches were prepared with $100 \%$ OPC and fiber volume fractions of $0 \% .0 .25,0.5,0.75,1.0$ and $1.25 \%$ (B1-B6). While another six batches were set with POFA replacing OPC by $20 \%$ for the same fiber volume fractions (B7B12).

\section{Test Program and Test Procedure}

The fresh state properties were investigated by using the slump and VeBe tests according to BS EN 12350-2:2009 and BS EN 12350-3:2009 respectively. The compressive strength test was led by $100 \mathrm{~mm}$ cube specimens (BS EN 12390-2:2009, BS EN 12390-3:2009). The cubic specimens of $100 \mathrm{~mm}$ that was used for compressive strength, were reloaded after failure to evaluate the post-failure compressive strength (PFCS). Cylindrical specimens measuring $100 \mathrm{~mm} \times 200 \mathrm{~mm}$ were prepared for splitting tensile strength test (ASTM C496/C496 M-11). For flexural strength test, prism specimens of $100 \mathrm{~mm} \times 100 \mathrm{~mm} \times 500 \mathrm{~mm}$ were made according to
Fig. 3 Collection and preparation of waste polypropylene carpet fiber

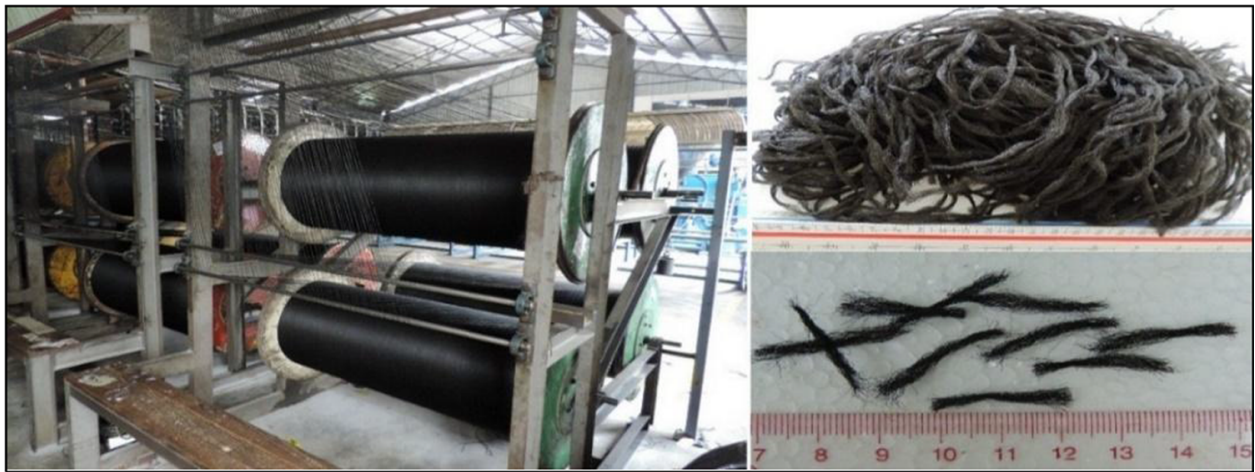


Table 2 Properties of polypropylene carpet fiber

\begin{tabular}{|c|c|c|c|c|c|c|}
\hline Fiber & Length (mm) & Diameter $(\mathrm{mm})$ & Density $\left(\mathrm{kg} / \mathrm{m}^{3}\right)$ & Tensile strength $(\mathrm{MPa})$ & Melting point $\left({ }^{\circ} \mathrm{C}\right)$ & Reaction with water \\
\hline Multi-filament & 20 & 0.45 & 910 & 400 & 170 & Hydrophobic \\
\hline
\end{tabular}

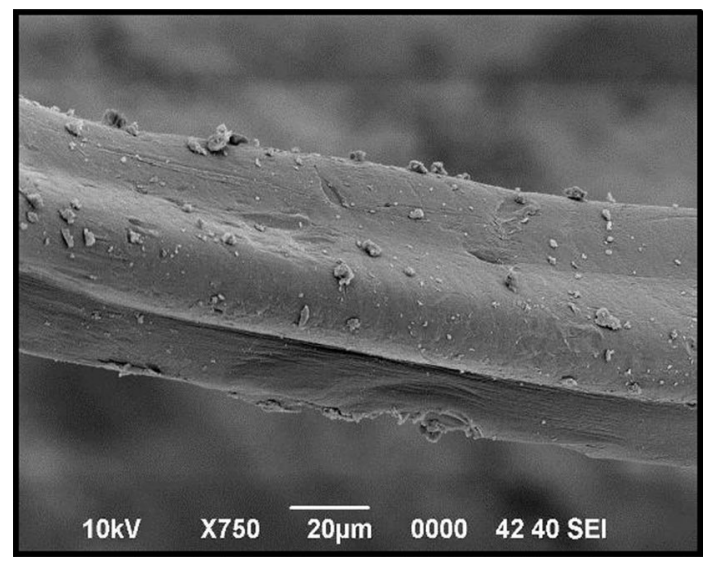

Fig. 4 SEM image of polypropylene waste carpet fiber

BS EN 12390-5:2009. A non-destructive test of ultrasonic pulse velocity (UPV) was led by using ultrasonic pulse velocity measuring device with amplitude adjustable from 250 to $1000 \mathrm{~V}$ having a measuring range of $0-3000 \mu \mathrm{s}$. The test was conducted before the compressive strength test on the $100 \mathrm{~mm}$ cube concrete specimens at the age of 7, 28 and 91 days following ASTM C597-09. Morphology and microstructure study were performed by SEM. The small particles were prepared for mixes after 91 days curing in water. The samples were coated with gold before the examination. The Impact resistance test of concrete was also performed in accordance with the ACI Committee
544-1999. Three discs of $150 \mathrm{~mm} \times 64 \mathrm{~mm}$ were prepared. The blow was achieved through a $4.45 \mathrm{~kg}$ hammer dropping over a $6.35 \mathrm{~cm}$ steel ball placed on the center of the top face of the specimen at a height of $45.7 \mathrm{~cm}$.

\section{Results and Discussion}

\section{Workability}

The experimental findings of the slump and VeBe time tests are illustrated in Fig. 5. Results indicated that the addition of polypropylene carpet fiber in fresh concrete increased $\mathrm{VeBe}$ time and decreased the slump values. Higher content of fiber in the mix exhibited a dryer consistency in fresh concrete which is indicated by the balling effect of fibers, binder and sand particles. Figure 5 reveals that the slump value of the control mixture without any fiber and POFA, was $210 \mathrm{~mm}$. After inclusion of fibers at volume fractions of $0.25,0.5,0.75,1$ and $1.25 \%$, the slump values decreased to $130,70,55,45$ and $25 \mathrm{~mm}$, respectively. The addition of POFA into the concrete mixture, is normally densify the matrix by filling the voids in the concrete composite (Awal and Shehu 2015). Therefore, it caused a stiffer matrix and therefore reduced the workability of the concrete. It is observed that by the replacement of $20 \%$ POFA, the slump values deceased more than that

Table 3 Concrete mixtures containing different amount of carpet fiber and POFA

\begin{tabular}{|c|c|c|c|c|c|c|c|}
\hline Mix & Cement $\left(\mathrm{kg} / \mathrm{m}^{3}\right)$ & POFA $\left(\mathrm{kg} / \mathrm{m}^{3}\right)$ & Water $\left(\mathrm{kg} / \mathrm{m}^{3}\right)$ & Fine agg. $\left(\mathrm{kg} / \mathrm{m}^{3}\right)$ & Coarse agg. $\left(\mathrm{kg} / \mathrm{m}^{3}\right)$ & $V_{\mathrm{f}}(\%)$ & $V_{\mathrm{f}}\left(\mathrm{kg} / \mathrm{m}^{3}\right)$ \\
\hline B1 & 455 & - & 215 & 840 & 870 & - & - \\
\hline B2 & 455 & - & 215 & 840 & 870 & 0.25 & 2.275 \\
\hline B3 & 455 & - & 215 & 840 & 870 & 0.50 & 4.550 \\
\hline B4 & 455 & - & 215 & 840 & 870 & 0.75 & 6.825 \\
\hline B5 & 455 & - & 215 & 840 & 870 & 1.0 & 9.100 \\
\hline B6 & 455 & - & 215 & 840 & 870 & 1.25 & 11.375 \\
\hline B7 & 364 & 91 & 215 & 840 & 870 & - & - \\
\hline B8 & 364 & 9 & 215 & 840 & 870 & 0.25 & 2.275 \\
\hline B9 & 364 & 91 & 215 & 840 & 870 & 0.50 & 4.550 \\
\hline B10 & 364 & 91 & 215 & 840 & 870 & 0.75 & 6.825 \\
\hline B11 & 364 & 91 & 215 & 840 & 870 & 1.0 & 9.100 \\
\hline B12 & 364 & 91 & 215 & 840 & 870 & 1.25 & 11.375 \\
\hline
\end{tabular}


Fig. 5 Effect of carpet fiber on a slump and $\mathbf{b} \mathrm{VeBe}$ time of OPC and POFA concrete mixtures

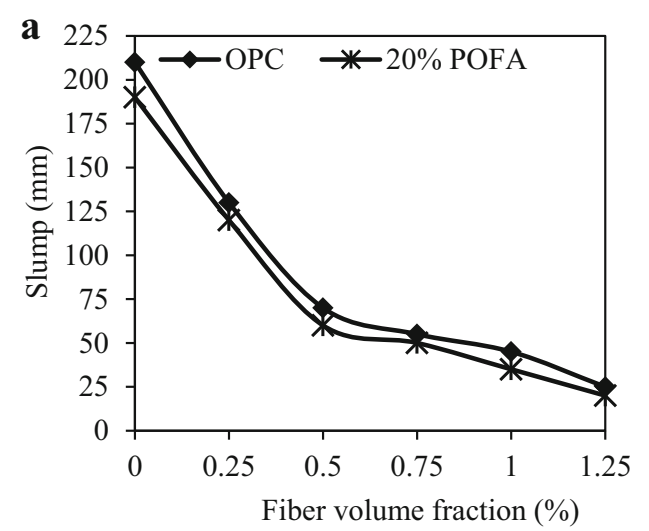

with OPC only. The combination of carpet fibers and POFA has also reduced the slump values of concrete mixtures, where slump values of $120,60,50,35$ and $20 \mathrm{~mm}$ were obtained for the same volume fractions respectively. It has also been observed that the addition of fiber at high volume fractions in the POFA based concrete mixtures resulted in higher $\mathrm{VeBe}$ time values.

\section{Compressive Strength}

Figure 6 demonstrates the variation in compressive strength of concrete mixtures. It can be seen that cube compressive strength was reduced by the inclusion of carpet fiber and POFA. Comparing with the control mix without any fiber and POFA, the addition of fibers at 0.25 , $0.5,0.75,1$, and $1.25 \%$ decreased the compressive strength by $6,7.5,11.15,18.06$, and $21.23 \%$ respectively at the age of 28 days. Reductions in compressive strength of 13.45 , 10.23 , and $3.22 \%$ are observed in concrete containing $20 \%$ POFA for the curing period of 7, 28 and 91 days as compared to OPC concrete, respectively. While in fibrous mixtures containing POFA and $0.5 \%$ fiber, for instance B9, the compressive strength was decreased by $18.2,16.3$ and $5.4 \%$ at the same curing time, compared to that of OPC concrete having the same amount of fiber. However, the addition of carpet fibers in the POFA-based mixtures significantly changed the failure mode of concrete from brittle to ductile as shown in Fig. 7. Due to bridging effect of the carpet fibers, the specimens did not crush, but held their integrity up to the end of the test. It has been found that, in early age mixtures containing POFA were weaker in compressive strength, however, higher strength was obtained after a longer period of curing due to the pozzolanic activity of POFA in the matrix. This indicates that the pozzolanic action of POFA and also the bridging effect of fiber can together improve the compressive strength of concrete at later ages.

The scanning electron micrograph (SEM) of content concrete mixtures containing OPC and POFA display the C-S-H gel formation. As seen in Fig. 8, at the age of 91 days, the $\mathrm{C}-\mathrm{S}-\mathrm{H}$ gel is more uniformly spared in POFA concrete over the OPC one. The finely spared of $\mathrm{C}-\mathrm{S}-\mathrm{H}$ gel and the formation of extra $\mathrm{C}-\mathrm{S}-\mathrm{H}$ gel due to consumption of portlandite by pozzolanic action of POFA caused in higher strength at a later age compared to the early age's strength. This is endorsed by the fact that the POFA modified the concrete matrix through the pozzolanic reaction and reduced the $\mathrm{Ca}(\mathrm{OH})_{2}$ content.
Fig. 6 Compressive strength of OPC and POFA carpet fiber reinforced concrete mixtures
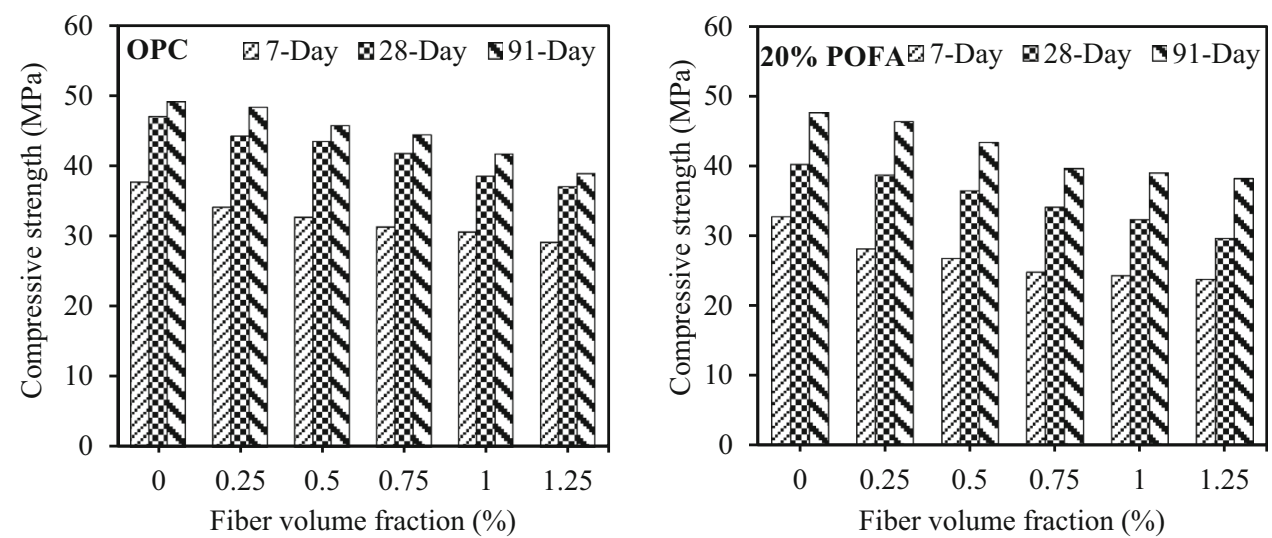

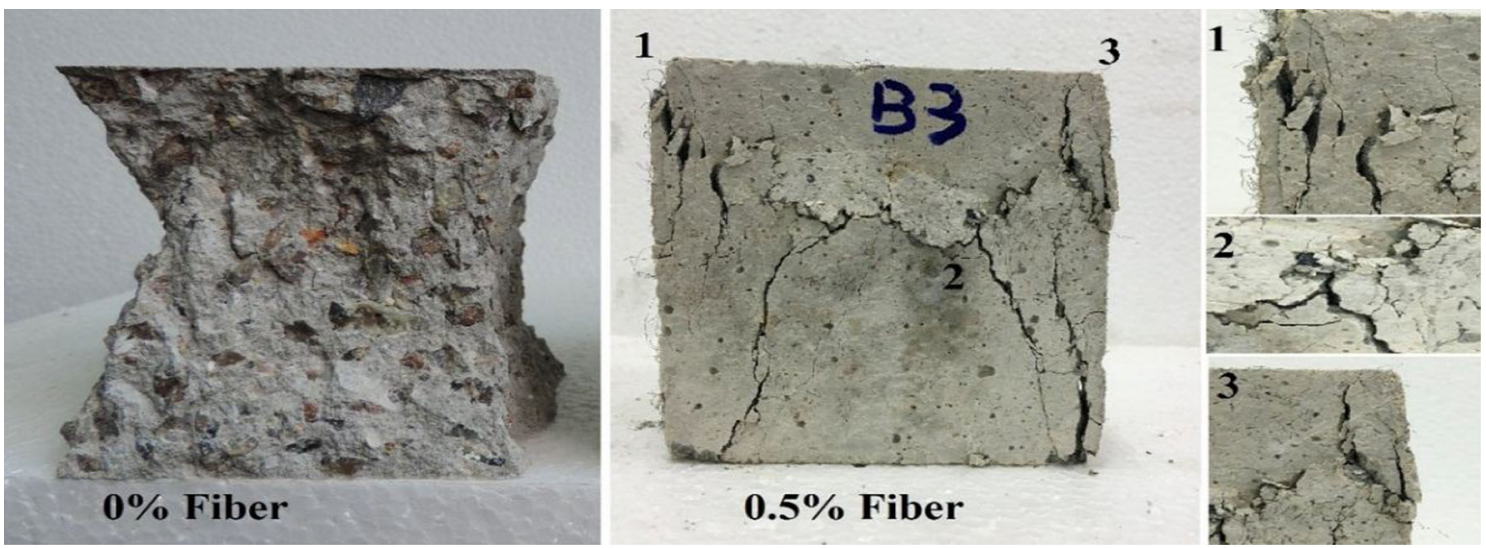

Fig. 7 Failure mode of concrete specimens under compression load

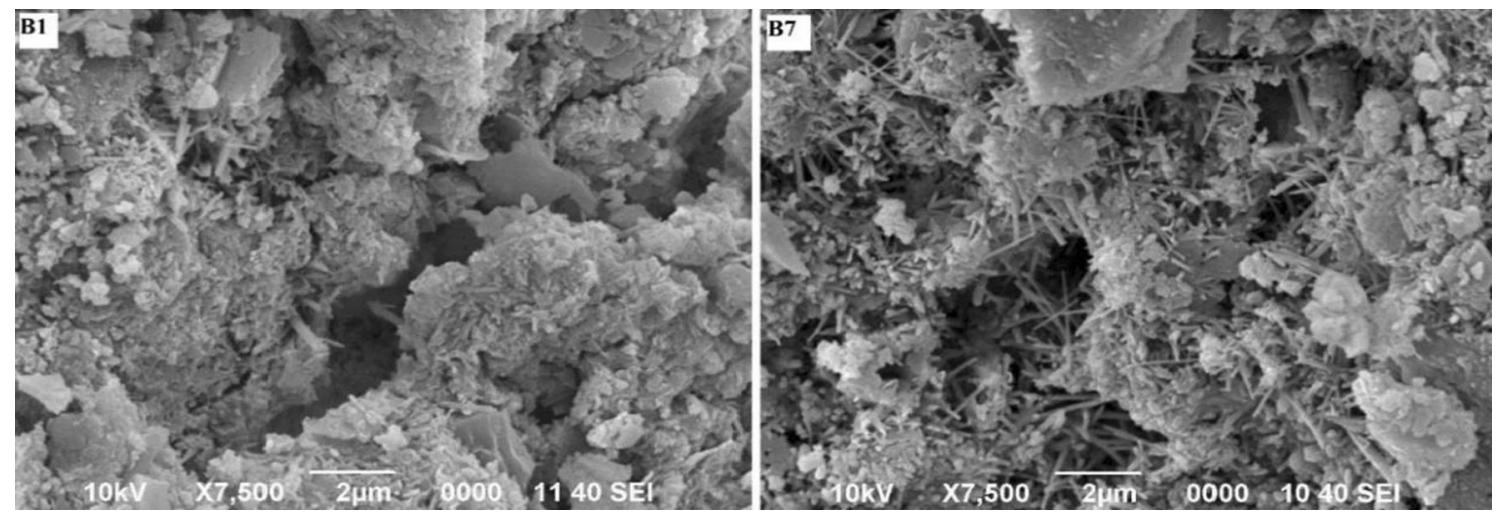

Fig. 8 SEM of OPC (B1) and POFA (B7) concrete mixtures at 91 days curing period

\section{Splitting Tensile Strength}

The influence of waste carpet fiber on the splitting tensile strength of concrete is illustrated in Fig. 9. It can be seen that the splitting tensile strengths of concrete specimens containing carpet fibers were significantly higher than that of the control concrete without any fiber. When the splitting occurred and sustained, the carpet fibers bridging the split parts of the specimens acted over the stress transfer from the matrix to the fibers and, therefore, supported the whole tensile stress (Fig. 10). The transferred stress ultimately increased the tensile strain capacity of the concrete matrix and, thus, improved the tensile strength of the fibrous mixtures over the non-fibrous concrete counterpart.

Figure 9 further demonstrates the combined effect of POFA and carpet fibers on the development of splitting tensile strength of concrete. For instance, the 28-day tensile strength of concrete with OPC alone were increased by
Fig. 9 Splitting tensile of OPC and POFA carpet fiber reinforced concrete mixtures
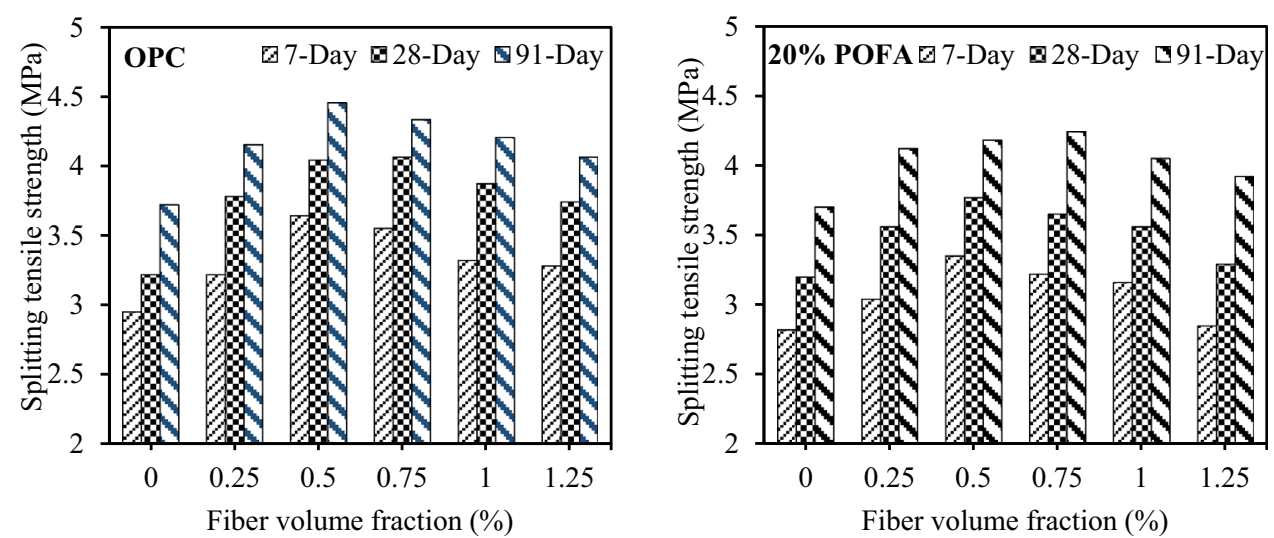
Fig. 10 Failure mode of concrete specimens under tensile load, and bridging action of the fibers

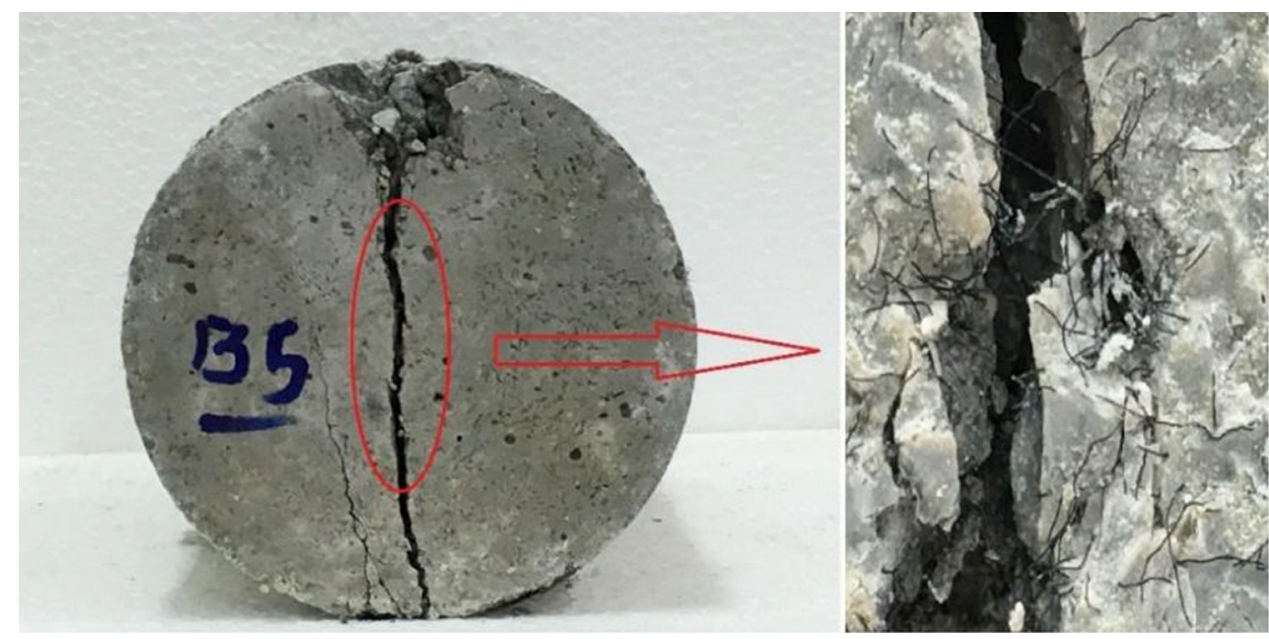

$17.4,25.5,26,20.2$ and $16.1 \%$ of the carpet fiber content of $0.25,0.5,0.75,1$ and $1.25 \%$, respectively, as compared to that of plain concrete without fiber. Inspection of the data reported in Fig. 9 indicates that the addition of fibers to POFA concrete mixtures produce an increase in the splitting tensile strength. The uses of $20 \%$ POFA produced comparable compressive and tensile strengths than that of OPC alone, but it gains the environmental benefits by $20 \%$ waste replacements. Presumably, this development was at lower rates as compared to the OPC mixtures at the early age due to lower hydration process of POFA. For both OPC and OPC with POFA mixtures, the addition of carpet fibers increased the measured splitting tensile strengths, reaching maxima for additions of $0.5-0.75 \%$ fiber volume fractions. This enhancement can be attributed to the higher contact area between fibers, cement paste and aggregates resulting in better performance of the concrete at a later age.

\section{Flexural Strength}

The experimental results of the flexural strength test are illustrated in Fig. 11. It has been observed that the flexural strength of concrete made with carpet fibers was significantly improved compared to that of concrete without fibers. A similar trend like that of tensile strength has also been observed in the development of flexural strength of fiber reinforced concrete. The highest flexural strength of 6.12 $\mathrm{MPa}$ was recorded for mixture having $0.5 \%$ fiber at the age of 91 days, which is $19.5 \%$ higher than that of control mix without POFA and fiber. Combination of carpet fibers and POFA, as contributing to the development of tensile strength, improved flexural performance, particularly at later ages. The increase in flexural strength resulted mainly from the fibers intersecting the cracks in the tension zone of the prism specimens. Carpet fibers hold the crack face separation through their stretching, providing a higher energy absorption capacity and also stress relaxing the microcracked area adjoining the tip of the crack (Fig. 12). However, further increase in fiber content resulted in lower flexural strength. This phenomena could be due to the decrease in the workability of the concrete at higher volume fractions in the mixtures. The higher amount of porosity may be linked to an inadequate compaction and a possible additional micro-cracks, unbounded fibers and cracks and also the poor fiber-matrix bonding.
Fig. 11 Flexural strength of OPC and POFA carpet fiber reinforced concrete mixtures
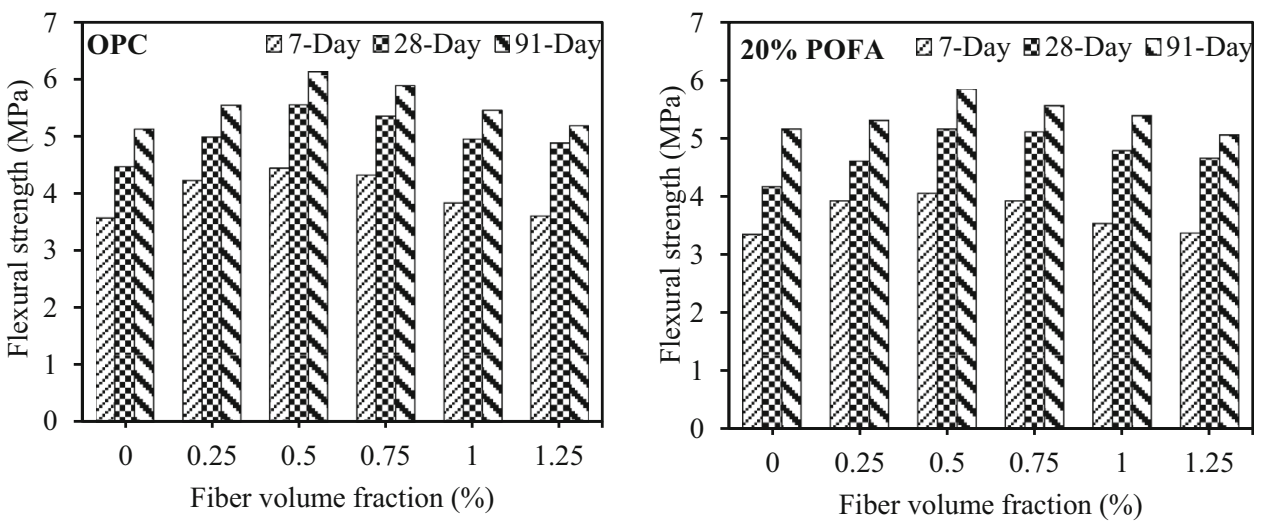
Fig. 12 Failure mode of concrete prism under flexural load
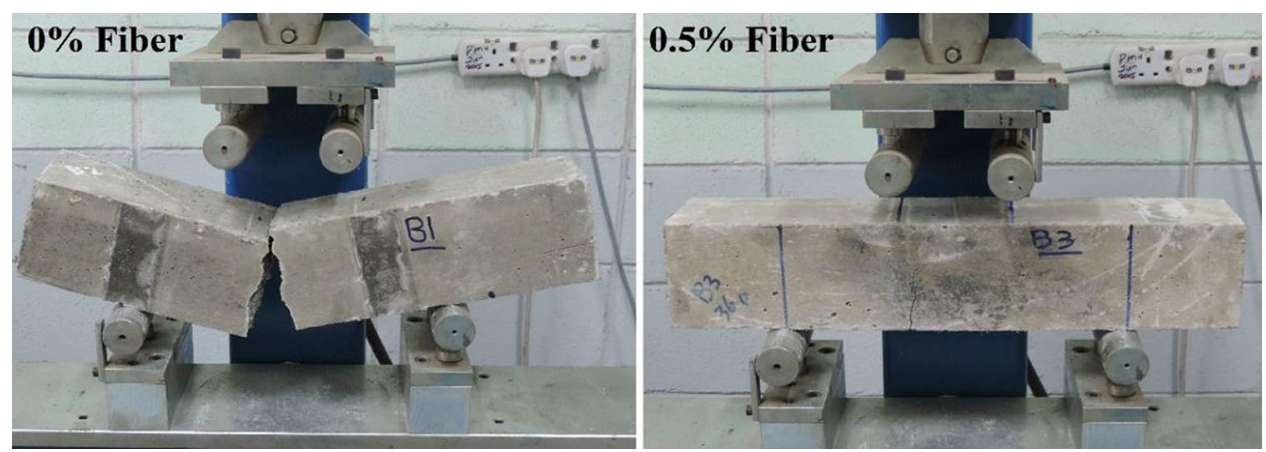

To estimate the bond characteristic of carpet fibers combined with POFA in the mixture, the microstructure of fiber reinforced concrete with $0.5 \%$ volume fraction of carpet fiber was tested through SEM. Figure 13a, b shows the fiber-matrix interface of the concrete composite containing carpet fibers and also bridging action of fibers after the fracture. The results of the tensile and flexural tests of concrete containing carpet fiber indicate a good fiber-matrix interface and better fiber-matrix bond.

\section{Post-Failure Compressive Strength}

The post-failure compressive strength (PFCS) is a simplified method to evaluate the post-failure compressive mode of concrete (Yap et al. 2013). After failure of the cubic specimens used in compressive strength (CS) test, the cubes were reloaded to measure their post-failure cube compressive strength. The data obtained for the PFCS of all concrete mixtures are displayed in Table 4 . The effect of carpet fibers on the fracture behavior of the matrix can be divided into two main parts. Firstly, the addition of carpet fiber inclines to decrease the maximum stress and also modulus of elasticity of the mixtures. Secondly, once the crack face bridging by grains fails, stress transfer through the cracks is possible via intersection between fibers and cracks. Higher ductility in the carpet fiber reinforced concrete occurs as a result of crack bridging action.

The addition of discontinuous carpet fibers in the concrete mixture decreases the uneven propagation of macrocracks and allows a ductile performance when the fibers can provide adequate loads to repress cracks opening and redistribute the stresses against the neighboring matrix. As a result, the post-failure performance of the concrete containing carpet fiber is more ductile than that of the plain concrete with a slow decrease in strength. Therefore, the addition of carpet fiber resulted in an increase of toughness and ductility of concrete, with a higher energy absorption, and a well distributed cracking.

It is interesting to note that the post-failure compressive strength was significantly increased with the increase in fiber content. As expected, Fig. 14 demonstrate that mixtures with polypropylene carpet fibers obtained higher PFCS than that of plain concrete. A further increase in fiber content, significantly affected on the PFCS of mixtures. On average, the mixtures with $0.25,0.5,0.75,1.0$ and $1.25 \%$ carpet fiber obtained a PFCS value of 36.2, 44.4, 48.1, 55.1 and $40.1 \%$ higher respectively than that observed for the control mixture (B1). The same tendency has been observed for the mixtures incorporating 20\% POFA but at the lower rates. For the same volume fractions of fiber, for example, the obtained values of PFCS were 31.1, 44.6,
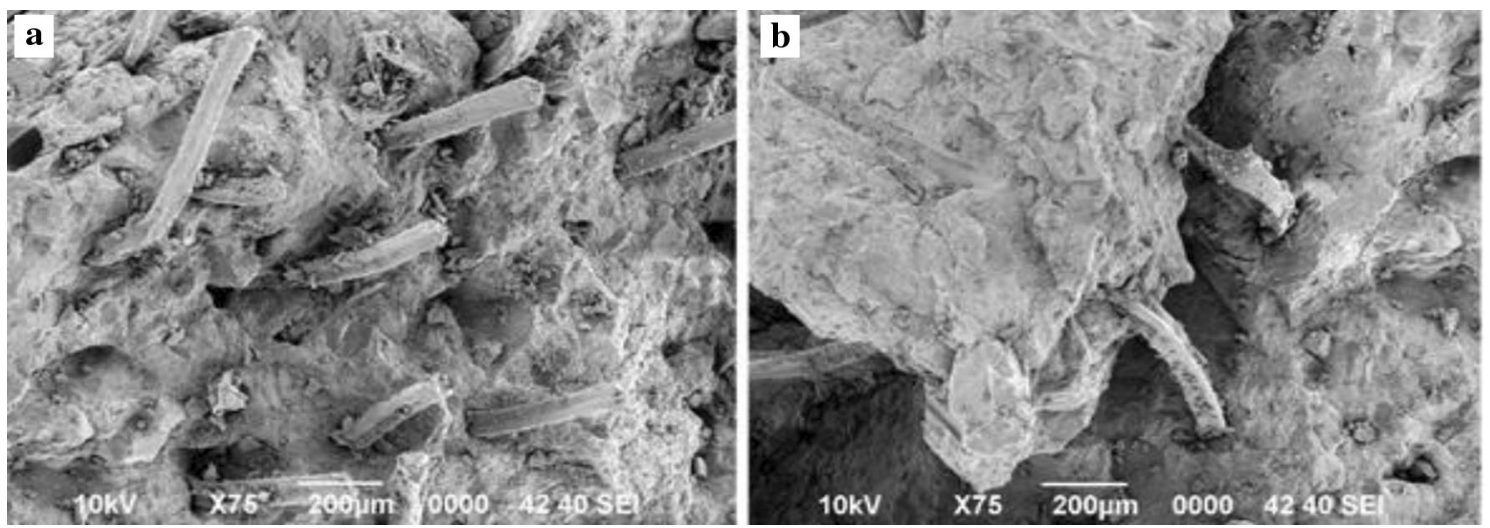

Fig. 13 SEM of a the fracture surface, $\mathbf{b}$ bridging action of concrete containing $0.5 \%$ carpet fiber at 91 days curing period 
Table 4 Post-failure compressive strength of concrete mixtures

\begin{tabular}{|c|c|c|c|c|c|c|c|c|}
\hline \multirow[t]{2}{*}{ Mix } & \multicolumn{2}{|l|}{ 7-Day } & \multicolumn{2}{|c|}{ 28-Day } & \multicolumn{2}{|c|}{ 91-Day } & \multirow[t]{2}{*}{ Average of $\% \mathrm{CS}$} & \multirow{2}{*}{$\begin{array}{l}\text { Increase with } \\
\text { relative to PC (\%) }\end{array}$} \\
\hline & PFCS & $\% \mathrm{CS}$ & PFCS & $\% \mathrm{CS}$ & PFCS & $\% \mathrm{CS}$ & & \\
\hline B1 & 15.4 & 40.9 & 24.51 & 52.16 & 25.9 & 52.8 & 48.6 & 100.0 \\
\hline B2 & 19.6 & 57.4 & 31.13 & 70.45 & 34.2 & 70.8 & 66.2 & 136.2 \\
\hline B3 & 21.1 & 64.6 & 31.87 & 73.34 & 32.6 & 71.3 & 69.7 & 143.4 \\
\hline B4 & 21.2 & 67.6 & 31.37 & 75.11 & 32.5 & 73.3 & 71.9 & 148.1 \\
\hline B5 & 22.1 & 72.1 & 30.43 & 79.03 & 31.3 & 75.2 & 75.4 & 155.1 \\
\hline B6 & 18.8 & 64.6 & 27.03 & 73.02 & 25.9 & 66.7 & 68.1 & 140.1 \\
\hline B7 & 10.7 & 32.7 & 20.30 & 48.12 & 27.9 & 58.9 & 46.5 & 95.7 \\
\hline B8 & 15.3 & 54.5 & 26.43 & 68.36 & 31.7 & 68.5 & 63.7 & 131.1 \\
\hline B9 & 16.5 & 61.5 & 28.30 & 77.82 & 30.9 & 71.6 & 70.3 & 144.6 \\
\hline B10 & 16.2 & 65.5 & 26.61 & 78.26 & 30.2 & 76.3 & 73.3 & 150.7 \\
\hline B11 & 17.1 & 70.5 & 25.67 & 79.61 & 29.1 & 74.9 & 75.1 & 154.2 \\
\hline B12 & 15.9 & 67.3 & 23.22 & 78.54 & 28.1 & 73.8 & 73.2 & 150.5 \\
\hline
\end{tabular}

PFCS post-failure compressive strength (MPa), $C S$ compressive strength (MPa), $P C$ plain concrete

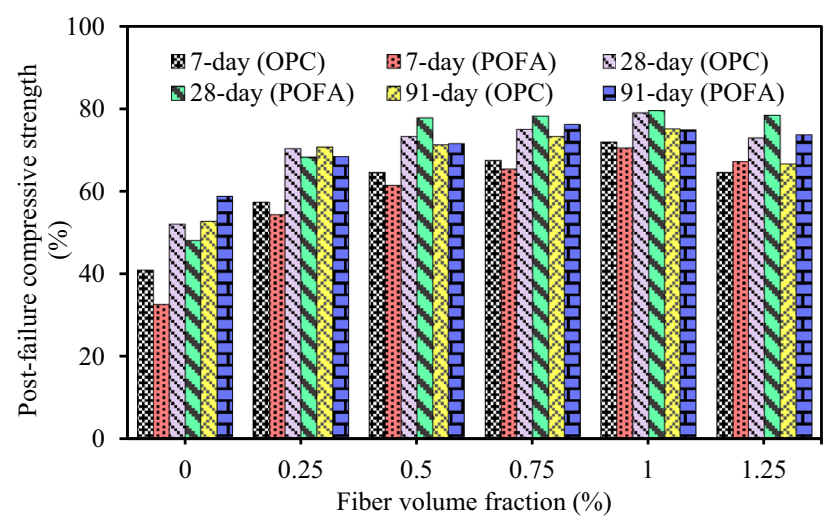

Fig. 14 Variation of PFCS with and without POFA vs fiber volume fraction

50.7, 54.2 and $50.5 \%$ higher than that of the control mixture. The results obtained in this study are in agreement with the observation made by Yap et al. (2013) and Lima et al. (2014) in the presence of polypropylene and natural fibers in fiber reinforced concrete.

\section{Impact Resistance}

The impact resistance of concrete for different volume fractions of carpet fiber was investigated in terms of the number of blows required for gaining first crack (N1) and ultimate failure (N2) of the concrete specimen. It has been found that, by the addition of polypropylene carpet fibers into the concrete mixtures, the number of blows at first crack was increased by $54,158,221,300$ and $367 \%$ for B1 to B6 mixes, respectively. The effect of POFA on the impact resistance of polypropylene carpet fiber concrete is shown in Fig. 15. Test results indicated that replacement of POFA decreased the impact resistance of carpet fiber reinforced concrete. This may be the result of lower strength of concrete due to the POFA replacement. A positive interaction has been also found between the POFA and fibers, in the sense that combination of fiber and POFA exhibited a better performance in terms of crack distribution and ductility nature of the specimens when compared with OPC concrete without any fibers and POFA as shown in Fig. 16.

In general, the increase in the impact resistance at first crack and ultimate failure seemed to be proportional to the increase of fiber content in both OPC and POFA based mixtures. Similar observations have been made by Nili and Afroughsabet (2010) for polypropylene and silica fume concrete and the improvement in impact resistance was attributed to high fiber volume fractions which are expected in bridging the cracks because of their higher bond resistance.

\section{Ultrasonic Pulse Velocity}

The ultrasonic pulse velocity (UPV) test is a non-destructive test to measure the quality and homogeneity of concrete specimens to designate the existence of pores and cracks. Figure 17 reveals the variation in UPV of concrete containing carpet fiber and POFA. It can be seen that the polypropylene carpet fiber produced no significant effect on the UPV values of concrete. However, UPV values increased with respect to time period post-cured. The UPV value of plain concrete without any fiber and POFA, for example, $4551 \mathrm{~m} / \mathrm{s}$ and $4575 \mathrm{~m} / \mathrm{s}$ at the age of 28 and 
Fig. 15 Impact resistance of concrete mixtures at first crack and at failure
Fig. 16 Crack distribution and ductility nature of the a OPC plain concrete and $\mathbf{b}$ concrete containing carpet fibers and POFA under impact loads
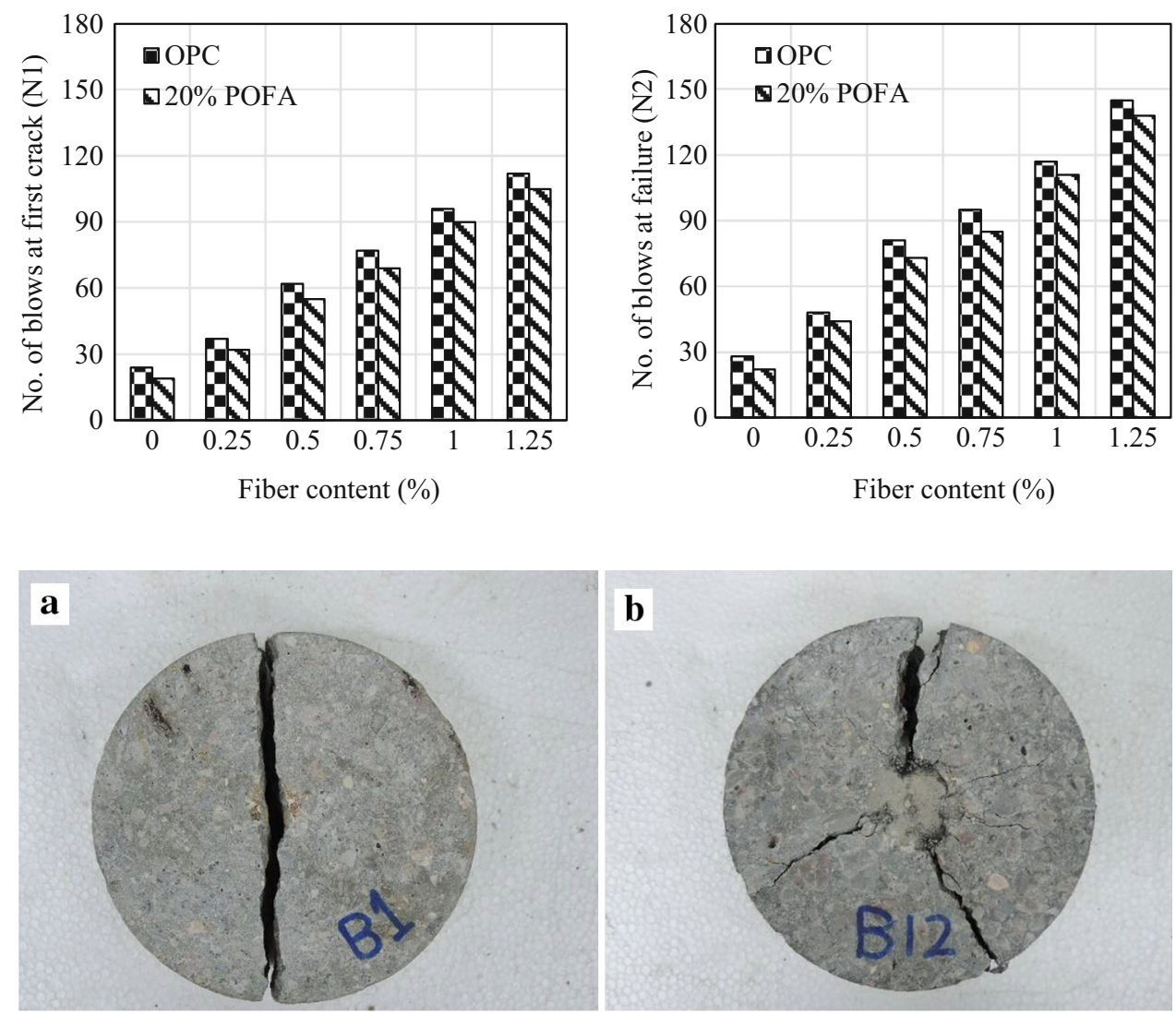

Fig. 17 Variation of ultrasonic pulse velocity of the concrete mixtures

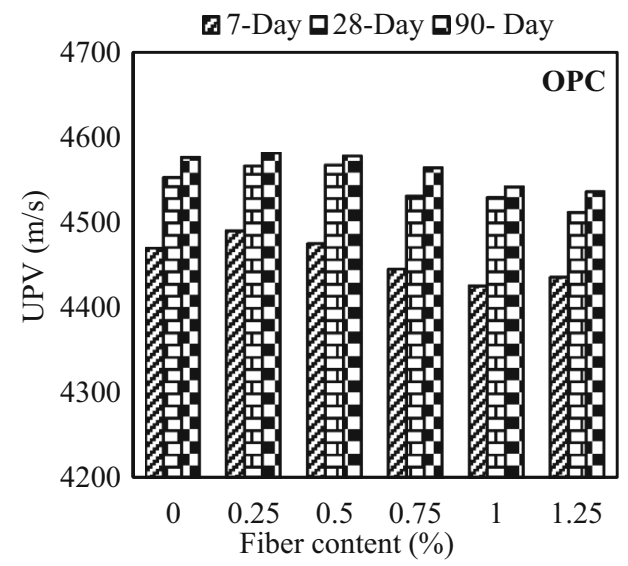

91 days respectively, and were evaluated to be excellent in-terms of concrete quality (Neville 1995).

The inclusion of carpet fiber raised the UPV values up to a certain volume fraction. Concrete specimens with 0.25 and $0.5 \%$ fiber obtained UPV values of 4581.1 and $4577 \mathrm{~m} / \mathrm{s}$ respectively at the age of 91 days which are greater than that of plain concrete. However, as expected, further increase in carpet fiber content caused a reduction in UPV values. It is generally understood that this decrease in the change of velocity is due to the presence of voids and micro-cracks that reduced homogeneity of the concrete specimens at higher fiber volume fractions. The inclusion of POFA to fibrous mixtures also increased the UPV values. The UPV values ranging from 4200 to $4600 \mathrm{~m} / \mathrm{s}$ were found, and is classified as good quality concrete for specimens containing carpet fiber and POFA at all ages.

It has been observed that the ultrasonic pulse velocity values can be correlated with their corresponding cube compressive strength. Figure 18 reveals the relationship between cube compressive strength and UPV values of concrete mixtures containing polypropylene carpet fiber and POFA. A good relationship between the UPV and 


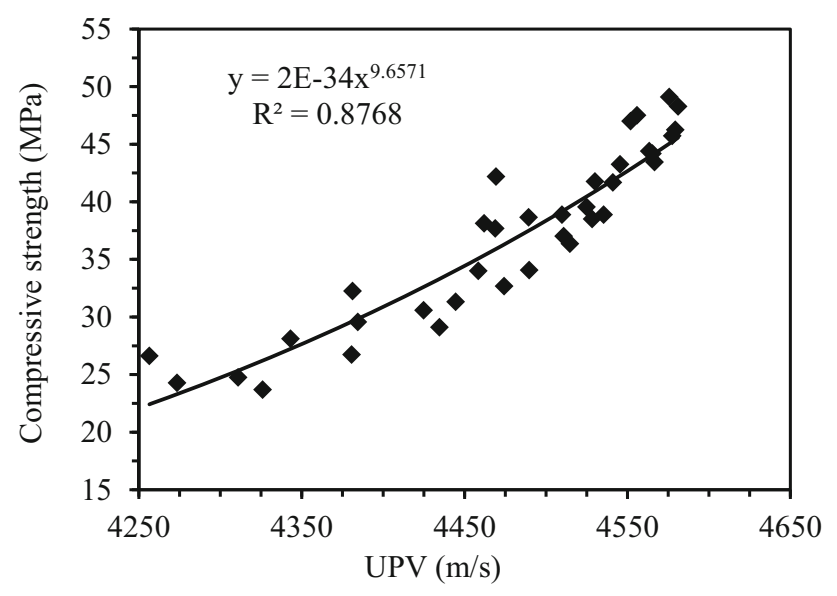

Fig. 18 Relationship between compressive strength and ultrasonic pulse velocity for concrete mixtures containing polypropylene carpet fiber and POFA

compressive strength can clearly be seen in Fig. 18. A power regression method was applied to correlate the experimental results in the following Eq. (1), having a coefficient of determination, $\mathrm{R}^{2}$ of 0.87 for all samples, which signifies a good confidence of the relationship.

$\mathrm{y}=2 \mathrm{E}-34 \mathrm{x}^{9.6571}$

\section{Conclusions}

The following conclusions were drawn based on the experimental data and the observations made in this research.

1. The addition and increase of carpet fiber in the mixtures, generally decreased the workability. The slump value of fibrous specimens having $1.25 \%$ fiber, decreased to $25 \mathrm{~mm}$ compared to $210 \mathrm{~mm}$ of OPC plain concrete. Combination of carpet fibers and POFA resulted lower workability of concrete mixtures. Generally, the higher the fiber content greater was the VeBe time.

2. Incorporation of waste carpet fiber generally reduced the compressive strength of concrete mixtures irrespective of POFA content. The maximum reduction in the early age (7 days) strength development occurred in $1.25 \%$ of fiber content by 22.6 and $36.9 \%$ for OPC and POFA mixtures respectively. With the increase in the curing period, say at 91 days, the reduction in strength development dropped down to 20.77 and $22.4 \%$ for OPC and POFA mixtures respectively. It is the pozzolanic behavior of POFA that contributed to the strength development of concrete with the increase in curing period.

3. The addition of carpet fibers to mixtures containing POFA had a positive effect on the tensile strength, and significantly improved the flexural strength of concrete mixtures. The maximum strength gain in both tensile and flexural strengths were observed in concrete specimens with $0.5 \%$ fiber addition at the age of 91 days.

4. The inclusion of polypropylene carpet fibers developed the post-failure compressive strength of concrete mixtures. The post-failure performance of the concrete containing carpet fiber is more ductile than that of the plain concrete resulting in an increase of toughness and ductility of concrete, with a higher energy absorption, and a well distributed cracking.

5. Carpet fibers increased the first crack and ultimate failure impact resistance of concrete. The impact resistance at ultimate failure was improved by 71 , $189,239,318$ and $418 \%$ with $0.25,0.5,0.75,1.0$, and $1.25 \%$ fiber volume fraction, respectively. Likewise, a similar tendency was observed in POFA content specimens, but at a lower rate.

6. The UPV values within the range of $4200-4600 \mathrm{~m} / \mathrm{s}$ were found, and is categorized as good quality concrete for specimens containing carpet fiber and POFA at all ages.

7. According to the microstructural analysis, interfacial interactions between carpet fiber, $\mathrm{C}-\mathrm{S}-\mathrm{H}$ gel and $\mathrm{Ca}(\mathrm{OH})_{2}$ of cementing materials produced a strong bonding, and increase the load-transfer capacity of the matrix.

8. The utilization of waste materials such as carpet fiber and palm oil fuel ash in concrete can demonstrate economic and technical advantages for the construction industry. Importantly, doing so many deliver environmental benefits through the more sustainable use of natural resources.

Acknowledgements The authors wish to thank the ENTEX Carpet Industries SND. BHD, Malaysia for making this research possible by providing the waste carpet fibers. The technical support received from staff of Structure and Materials laboratory of the Universiti Teknologi Malaysia (UTM) is also acknowledged.

\section{References}

Aldahdooh M, Bunnori Muhamad N, Johari MAM (2014) Influence of palm oil fuel ash on ultimate flexural and uniaxial tensile strength of green ultra-high performance fiber reinforced cementitious composites. Mater Des 54:694-701

Awal ASMA, Mohammadhosseini H (2016) Green concrete production incorporating waste carpet fiber and palm oil fuel ash. J Clean Prod 137:157-166

Awal ASMA, Shehu I (2015) Performance evaluation of concrete containing high volume palm oil fuel ash exposed to elevated temperature. Constr Build Mater 76:214-220

Awal ASMA, Mohammadhosseini H, Hossain MZ (2015) Strength, modulus of elasticity and shrinkage behaviour of concrete containing waste carpet fiber. Int J GEOMATE 9(1):1441-1446 
Brandt AM (2008) Fibre reinforced cement-based (FRC) composites after over 40 years of development in building and civil engineering. Compos Struct 86:3-9

Hsie M, Tu C, Song P (2008) Mechanical properties of polypropylene hybrid fiber-reinforced concrete. Mater Sci Eng, A 492:153-157

Karahan O, Atis CD (2011) The durability properties of polypropylene fiber reinforced fly ash concrete. Mater Des 32:1044-1049

Khankhaje E, Hussin MW, Mirza J, Rafieizonooz M, Salim MR, Siong HC, Warid MNM (2016) On blended cement and geopolymer concretes containing palm oil fuel ash. Mater Des 89:385-398

Lim NHAS, Ismail MA, Lee HS, Hussin MW, Sam ARM, Samadi M (2015) The effects of high volume nano palm oil fuel ash on microstructure properties and hydration temperature of mortar. Constr Build Mater 93:29-34

Lima P, Toledo Filho RD, Melo Filho JA (2014) Compressive stressstrain behaviour of cement mortar-composites reinforced with short sisal fibre. Mater Res 17(1):38-46

Mohamadi MR, Mohandesi JA, Homayonifar M (2013) Fatigue behavior of polypropylene fiber reinforced concrete under constant and variable amplitude loading. J Compos Mater 47(26):3331-3342

Mohammadhosseini H, Awal ASMA (2013) Physical and mechanical properties of concrete containing fibers from industrial carpet waste. Int J Res Eng Technol 2(12):464-468

Mohammadhosseini H, Awal ASMA, Ehsan AH (2015) Influence of palm oil fuel ash on fresh and mechanical properties of selfcompacting concrete. Sadhana 40(6):1989-1999

Mohammadhosseini H, Awal ASMA, Sam ARM (2016) Mechanical and thermal properties of prepacked aggregate concrete incorporating palm oil fuel ash. Sadhana 41(10):1235-1244
Neville AM (1995) Properties of concrete, 4th ed. Longman Group Ltd, London

Nili M, Afroughsabet V (2010) The effects of silica fume and polypropylene fibers on the impact resistance and mechanical properties of concrete. Constr Build Mater 24(6):927-933

Papadakis V (2000) Effect of supplementary cementing materials on concrete resistance against carbonation and chloride ingress. Cem Concr Res 30(2):291-299

Schmidt H, Cieslak M (2008) Concrete with carpet recyclates: suitability assessment by surface energy evaluation. Waste Manag 28:1182-1187

Sisomphon K, Franke L (2007) Carbonation rates of concretes containing high volume of pozzolanic materials. Cem Concr Res 37(12):1647-1653

Sotayo A, Green S, Turvey G (2015) Carpet recycling: a review of recycled carpets for structural composites. Environ Technol Innov 3:97-107

Tay J, Show K (1995) Use of ash derived from oil-palm waste incineration as a cement replacement material. Resour Conserv Recycl 13:27-36

Wang Y (2010) Fiber and textile waste utilization. Waste Biomass 1:135-143

Wang Y, Wu H, Li V (2000) Concrete reinforcement with recycled fibers. J Mater Civ Eng 12:314-319

Yap S, Alengaram U, Jumaat MZ (2013) Enhancement of mechanical properties inpolypropylene-and nylon-fibre reinforced oil palm shell concrete. Mater Des 49:1034-1041

Zhang P, Li Q, Sun Z (2011) Influence of silica fume and polypropylene fiber on fracture properties of concrete composite containing fly ash. J Reinf Plast Compos 30(24):1977-1988 